\title{
Antioxidant Activity, HPTLC Fingerprint, and Discriminant Analysis of Plantago major Leaves from Diverse Origins in Indonesia
}

\author{
Kartini Kartini ${ }^{1, *}$, Christina Avanti ${ }^{2}$, Chutima Phechkrajang ${ }^{3}$, Omboon Vallisuta ${ }^{4}$
}

Kartini Kartini ${ }^{1, *}$, Christina

Avanti $^{2}$, Chutima Phechkrajang ${ }^{3}$, Omboon Vallisuta ${ }^{4}$

'Department of Pharmaceutical Biology, Faculty of Pharmacy, University of Surabaya, Raya Kalirungkut Road, Surabaya 60293, INDONESIA.

${ }^{2}$ Department of Pharmaceutic, Faculty of Pharmacy, University of Surabaya, Raya Kalirungkut Road, Surabaya 60293, INDONESIA.

${ }^{3}$ Department of Pharmaceutical Chemistry, Faculty of Pharmacy, Mahidol University, 447 Sri-Ayudhaya Road, Ratchathewi, Bangkok 10400, THAILAND.

${ }^{4}$ Department of Pharmacognosy, Faculty of Pharmacy, Mahidol University, 447 Sri-Ayudhaya Road, Ratchathewi, Bangkok 10400, THAILAND.

\section{Correspondence}

\section{Kartini Kartini}

Department of Pharmaceutical Biology,

Faculty of Pharmacy, University of

Surabaya, Raya Kalirungkut Road, Surabaya 60293, INDONESIA.

E-mail: kartini@staff.ubaya.ac.id

History

- Submission Date: 17-09-2019;

- Review completed: 13-10-2019;

- Accepted Date: 18-10-2019.

DOI : 10.5530/pj.2019.11.229

Article Available online http://www.phcogj.com/v11/i6s

\section{Copyright}

(C) 2019 Phcogi.Com. This is an openaccess article distributed under the terms of the Creative Commons Attribution 4.0 International license.

\begin{abstract}
Introduction: Plantago major L. (Plantaginaceae) is a perennial herb having contribution to the folk medicine all around the world, including Indonesia with wide geographical distribution. Plant materials origin is one factor that significantly influences the quality of herbal medicines. Materials and Methods: In this paper, High-Performance Thin Layer Chromatography (HPTLC) method using pattern-oriented approach has been employed to evaluate the quality of Plantago major leaves collected from seven origins in Indonesia. To differentiate the antioxidant capacities of those plant materials, the crude extracts were tested using 1,1-diphenyl-2-picrylhydrazyl (DPPH), total phenolics, and total flavonoids assay methods. Results: The results showed that radical scavenging activity, total phenolics, and total flavonoids of plant material from seven origins were significantly different. Moreover, HPTLC fingerprints analyzed with chemometrics showed an ability to discriminate the leaves samples from various origins as well as detect chemicals responsible for discrimination. Two models using principal component analysis (PCA) and partial least squares (PLS-DA) were built in chemometrics test. The PCA model was able to describe the studied samples by using four principal components with a value of explained variance of $95 \%$, whereas PLS-DA model accurately classified the leaves samples with prediction ability of $100 \%$. In the PCA, loading plot of the first PC showed that peaks number 10 and 12 are the most important peaks for clustering of the samples. Conclusions: Plantago major collected from different origins revealed different radical scavenging activity and concentration of total phenolics as well as total flavonoids. HPTLC fingerprints coupled with chemometrics analysis can be used as an alternative to marker-oriented method for the quality control of Plantago major.
\end{abstract}

Key words: Chemometrics, Flavonoids, Herbal medicines, Pattern-oriented, Phenolics, PLSDA.

\section{INTRODUCTION}

Plantago major L. (Plantaginaceae) is a perennial herb that has contributed to the folk medicine all around the world, ${ }^{1}$ including Indonesia with wide geographicaldistribution. ${ }^{2}$ Diverse pharmacological effects have been demonstrated for $P$. major such as anti-inflammatory, ${ }^{3-7}$ wound healing, ${ }^{8}$ antiviral, ${ }^{9,10}$ anticancer, ${ }^{9,11}$ anticholinesterase, ${ }^{12}$ and immunomodulator. ${ }^{913}$ Additionally, this plant has been investigated for its antioxidant activity. ${ }^{12,14}$ The leaves are the most being part used in traditional medicine around the world.

The effect of parts of plant and their growing environment to the chemical compounds of herbal materials have been shown in many studies ${ }^{15-18}$ and it is therefore necessary to determine their contents and compositions to assure the consistency of biological activity and to anticipate their potential adverse effects. ${ }^{19}$ Marker(s) or biologically active constituents in herbs are commonly employed in quality assessment of herbal medicines. ${ }^{20}$ However, this parameter is not always worthy; for instance when the effect of growing condition is required. Since there are tens or even hundreds of constituents, which are slightly different according to their geographical locations, we cannot select only one or several markers as standard. In this case, fingerprint techniques are more recommended for those purposes. ${ }^{21,22}$

A fingerprint is a distinctive profile or pattern of sample which chemically reflects its composition in which as much information as possible is presented and can be developed by spectroscopy, chromatography or electrophoresis methods. ${ }^{19,22}$ Chromatographic fingerprint, especially HPTLCfingerprint, has been widely used in herbal medicines assessment due to its simplicity, rapidity, and economy. It is possible to visually analyze HPTLC-chromatograms; however, this technique is subjective and not quantitative. Moreover, fingerprint chromatograms are complex multivariate data sets which cause difficulty in evaluation of very similar chromatograms. Thus, chemometrics should be taken into consideration. This approach, although more difficult, is based only on objective mathematical methods and treats the chromatogram as a unique signal, without a need to identify and

Cite this article: Kartini K, Avanti C, Phechkrajang C, Vallisuta O. Antioxidant Activity, HPTLC Fingerprint, and Discriminant Analysis of Plantago major Leaves from Diverse Origins in Indonesia. Pharmacog J. 2019;11(6)Suppl:1483-9. 
interpret the peaks. Therefore, it provides a good possibility for mining more useful chemical information from original-rich data. ${ }^{22-24}$

In our previous work, we established a method to determine the concentration of ursolic acid and oleanolic $\operatorname{acid}^{25}$ in different plant organs of $P$. major. Nevertheless, the leaves part did not contain oleanolic acid. On the other hand, we observed that leaves extract exhibited the highest DPPH scavenging activity among the other parts. Previous studies supposed that phenolics and flavonoids substances are the most responsible for antioxidant activity of Plantago. ${ }^{26}$ Therefore, standardization of $P$. major leaves using fingerprints accompanied with the antioxidant capacity seems more appropriate.

As a continuation of our previous work, in this present study we determined radical scavenging activity, total phenolics, and flavonoids contents in P. major leaves collected from several origins in Indonesia. We developed also the HPTLC fingerprints combined with chemometrics to differentiate those leaves samples. Although several works both on qualitative and quantitative evaluation of Plantago $\mathrm{L}$. have been reported, ${ }^{27-30}$ none of them involved comparison between $P$. major from different origins using chemometrics approach. Majority of the present studies focused on the application of marker(s). Therefore, this present study was aimed to (1) determine radical scavenging activity, total phenolics, and total flavonoids of $P$. major leaves extracts collected from various origins in Indonesia, and (2) discriminate $P$. major leaves samples from those origins using HPTLC fingerprint combined with chemometrics method.

\section{MATERIAL AND METHODS}

\section{Chemicals}

The following chemicals were procured from Sigma (St. Louis, MO, USA): gallic acid, quercetin, and 2,2-Diphenyl-1-picrylhydrazyl (DPPH). Folin-Ciocalteu (FC) reagent was from Fisher Scientific, Leicestershire, U.K. HPTLC plate pre-coated with silica gel $60 \mathrm{~F}_{254}$ was from Merck KGaA (Darmstadt, Germany). All other reagents used in this study were of analytical grade.

\section{Plant materials}

Plantago major samples were collected from seven origins in Indonesia (Table 1). Whole plant materials were harvested and cleaned with tap water. Leaves were separated from the other organs and used for this study. All samples were dried, ground, and authenticated as described in previous work i.e. by Center of Information and Development of Herbal Medicine, University of Surabaya, Indonesia with certificate number: 1101/D.T/XI/2013. ${ }^{25}$

\section{Extracts preparation}

Plantago major leaves extracts were prepared as detailed in our previous study ${ }^{25}$. Briefly, 10 grams of dry ground leaves were soaked three times ( $24 \mathrm{~h}$ each) in $100 \mathrm{ml}$ methanol, subsequently filtered, and evaporated under vacuum to dryness.

Table 1: Geographical origins of $P$. major leaves samples from Indonesia.

\begin{tabular}{ccccc}
\hline \multirow{2}{*}{ Location } & \multicolumn{2}{c}{ Position } & $\begin{array}{c}\text { Time of } \\
\text { collection }\end{array}$ & Sample code \\
\cline { 2 - 4 } & Latitude & Longitude & L1 \\
\hline Lumajang & $8^{\circ} 8^{\prime} 0^{\prime \prime} S$ & $113^{\circ} 13^{\prime} 1^{\prime \prime} \mathrm{E}$ & October, 2012 & L \\
Makassar & $5^{\circ} 8^{\prime} 37.2^{\prime \prime} \mathrm{S}$ & $119^{\circ} 25^{\prime} 34.8^{\prime \prime} \mathrm{E}$ & June, 2012 & L2 \\
Trawas & $7^{\circ} 40^{\prime} 12^{\prime \prime} \mathrm{S}$ & $112^{\circ} 36^{\prime} 36^{\prime \prime} \mathrm{E}$ & April, 2012 & L3 \\
Agam & $0^{\circ} 13^{\prime} 15.48^{\prime \prime} \mathrm{S}$ & $100^{\circ} 10^{\prime} 13.2^{\prime \prime} \mathrm{E}$ & April, 2012 & L4 \\
Solok Selatan & $1^{\circ} 29^{\prime} 7.0^{\prime \prime} \mathrm{S}$ & $100^{\circ} 10^{\prime} 13.2^{\prime \prime} \mathrm{E}$ & April, 2012 & L5 \\
Lampung & $2^{\circ} 11^{\prime} 16.4^{\prime \prime} \mathrm{S}$ & $101^{\circ} 3^{\prime} 40.4^{\prime \prime} \mathrm{E}$ & June, 2012 & L6 \\
Surabaya & $7^{\circ} 17^{\prime} 24^{\prime \prime S}$ & $113^{\circ} 53^{\prime} 33.2^{\prime \prime} \mathrm{E}$ & August, 2012 & L7 \\
\hline
\end{tabular}

\section{DPPH radical scavenging activity}

Free radical scavenging assay was carried out according to Galvez et al. with slight modification. ${ }^{26}$ A $50 \mu \mathrm{l}$ of $0.026 \%$ DPPH in methanol was added to $100 \mu$ of each dilution of extracts in methanol (total volume $150 \mu \mathrm{l})$. After $15 \mathrm{~min}$ incubation in darkness, absorbance was measured at $517 \mathrm{~nm}$ using a microplate reader. The concentration which produced $50 \%$ radical scavenging $\left(\mathrm{IC}_{50}\right.$ value) was extrapolated from the linear regression of concentration versus inhibition (\%). ${ }^{31}$

\section{Determination of total phenolics compounds}

Determination of the total phenolics content using Folin-Ciocalteu reagent was performed according to the established method, ${ }^{14}$, ${ }^{32}$ customized for 96-well microplates. Gallic acid, prepared in 8 concentrations ranging from 8 to $1000 \mu \mathrm{g} / \mathrm{ml}$, was used as a standard. Thirty $\mu \mathrm{l}$ of each extract or standard solution was added to $150 \mu \mathrm{l}$ of 0.1 $\mathrm{mol} / \mathrm{l} \mathrm{FC}$ reagent and mixed with $120 \mu \mathrm{l}$ of sodium carbonate (7.5\%) after $10 \mathrm{~min}$. Absorbance at $760 \mathrm{~nm}$ was read after $2 \mathrm{~h}$. The phenolics concentration was determined by comparison with the standard calibration curve of gallic acid, and the results are presented as a mean value of triplicate tests. The total phenol value was expressed as gram of gallic acid equivalents (GAE) per 100 gram of dry extracts.

\section{Determination of total flavonoids}

The aluminum chloride colorimetric method described by Chang et al., ${ }^{33}$ adapted for 96 -well microplates, was used to determine the total content of flavonoids. Quercetin solution was prepared ranging from 8 to $1000 \mu \mathrm{g} / \mathrm{ml}$ and used as a standard. Thirty microliters of extract or standard solution was diluted with $90 \mu \mathrm{l}$ of methanol, and $6 \mu \mathrm{l}$ of $10 \% \mathrm{AlCl}_{3}$ (substituted with distilled water in blank), $6 \mu \mathrm{l}$ of $1 \mathrm{~mol} / \mathrm{l}$ potassium acetate, and $170 \mu \mathrm{l}$ of distilled water were added. Absorbance at $415 \mathrm{~nm}$ was determined after $30 \mathrm{~min}$. All samples were analyzed in triplicate, and mean values of flavonoid content are expressed as gram of quercetin equivalents $(\mathrm{QE})$ per 100 of dry extracts calculated according to the standard calibration curve.

\section{HPTLC fingerprint analysis}

\section{Chromatographic measurement}

Each leaves extract was weighted $(15.0 \mathrm{mg})$ in 5 replicates, dissolved in $5.0 \mathrm{ml}$ methanol, filtered using nylon membrane filter $(0.45 \mu \mathrm{m})$, and then proceeded for HPTLC analysis using the following condition. A Camag TLC system comprising of Linomat 5 sample applicator, twinthrough chamber, TLC Plate Heater III, TLC Scanner 3, winCATS 1.2.6 software, and Reprostar 3 (Camag, Muttenz, Switzerland) were used. Chromatography was performed on HPTLC plates $20 \times 10 \mathrm{~cm}$, pre-coated with silica gel $60 \mathrm{~F}_{254}, 0.20 \mathrm{~mm}$ layer thickness (Merck, Darmstaadt, Germany) with a $100-\mu \mathrm{l}$ Camag syringe. Samples were spotted under a flow of nitrogen as $6 \mathrm{~mm}$ bands, $15 \mathrm{~mm}$ from the left edge, $10 \mathrm{~mm}$ from the bottom edge and $10 \mathrm{~mm}$ of track distance. Development was carried out in a chamber previously equilibrated (for $20 \mathrm{~min}$ at room temperature) with mobile phase, i.e. $30 \mathrm{ml}$ of 1,4 dioxane-xylene-propan-2-ol-12.5\% $\mathrm{NH}_{3}$ (1:2:5:2) and migration distance was $80 \mathrm{~mm}$. The plates were dried under warm air and dipped in 5\% sulfuric acid in methanol. Prior to densitometry scanning, TLC plates were dried in fume hood and then heated for $3 \mathrm{~min}$ at $120^{\circ} \mathrm{C}$. Fingerprints evaluation were carried out after scanning in absorbance mode at $545 \mathrm{~nm}$; with scanning speed $20 \mathrm{~mm} / \mathrm{s}$ using slit dimension 6 $\mathrm{mm} \times 0.45 \mathrm{~mm}$ and data resolution $100 \mu \mathrm{m} / \mathrm{step}$. The photographs were captured under white light.

\section{Chemometrics analysis}

Before applying the chemometrics technique, chromatographic data arrangement was conducted; i.e. (a) determine the peaks which can 
be distinguished from the background noise; (b) describe the peaks intensity (height or area) for all detected peaks, and; (c) present the data in the data matrix.

Principal component analysis (PCA), an exploratory data analysis, was employed as the first step in fingerprints analysis. This method is based on the information available in the fingerprints only. PCA reduces the complexity of the multivariate data set by explaining the correlation amongst a large number of variables in terms of a smaller number of underlying factors (principal components or PCs) without losing much information. The projections of the $\mathrm{n}$ objects from the original data on PCs are called the scores plots, whereas the contribution of each original variable to the score is presented by its loading, which detects the variables responsible for the clustering. ${ }^{19}$

The results of PCA were confirmed by a supervised analysis, i.e. partial least squares-discriminant analysis (PLS-DA). It is a regression extension of PCA and its principle comprises of the separation of deductive given classes of objects. ${ }^{19}$ This technique was conducted to develop "a model" that can be used to verify the geographical provenance of $P$. major. This was carried out on the total 35 chromatograms. These chromatograms were divided into training set and validation set. The former set consisted of four chromatograms from each location which were randomly selected. The subsequent set comprised of the remaining a chromatogram from each location. PCA and PLS-DA were carried out using Unscrambler ${ }^{\mathbb{B}} 9.8$ from CAMO AS (Trondheim, Norway).

\section{Statistical analysis}

All values were presented as mean \pm SEM or mean \pm SD, $n=3$. For multiple variables comparison, data were analyzed by ANOVA followed by Tukey test using GraphPad Prism statistical software (GraphPad Software Inc. Windows Version 5.01). Differences were considered to be significant at $P<0.05$.

\section{RESULTS AND DISCUSSION}

\section{Antioxidant activity of extracts}

Radical scavenging activity of the $P$. major leaves extracts was screened against DPPH radicals. The $\mathrm{IC}_{50}$ values were compared for the seven extracts tested (Table 2). Samples from Solok Selatan and Agam showed the highest scavenging activity $(P<0.05)$, with $\mathrm{IC}_{50}$ values of 133.37 and $160.80 \mu \mathrm{g} / \mathrm{ml}$, respectively. Three other samples, that is, those from Lumajang, Trawas, and Surabaya showed the next highest activity. The samples with the weakest scavenging potency were from Makassar and Lampung. Therefore, the scavenging activity of the samples in decreasing order was Solok selatan $>$ Agam $>$ Surabaya $>$ Trawas $>$ Lumajang $>$ Lampung $>$ Makassar. Using DPPH method, Beara et al. showed that $\mathrm{IC}_{50}$ value of $P$. major extract was $5.35 \mu \mathrm{g} / \mathrm{ml} .{ }^{14}$ The differences with the finding of this current study could be caused by various factors such as origin of the plant material as well as the type of extract. Previous study was carried out on aqueous methanol extract purified with petroleum ether whereas this current report has been conducted on total methanol extract. It indicated that phytochemicals constituent responsible for antioxidant activity is polar compounds.

Total phenolic and flavonoid compounds in all samples were determined by the Folin-Ciocalteu assay and the aluminum chloride colorimetric method, respectively. Serial dilution of gallic acid $\left(\mathrm{r}^{2}=\right.$ $0.993)$ and quercetin $\left(r^{2}=0.957\right)$ were used as standards to set the calibration curves, which were used to calculate the total phenolic and flavonoid contents for each extract. Table 3 presents total phenolic content as well as total flavonoid compounds calculated for each extract. When the phenolic and flavonoid contents of each extract were compared with the others, it could be observed that $P$. major leaves from Agam (L4) was the highest.
Table 2: $I C_{50}$ value of DPPH scavenging activity by extracts of $P$. major leaves.

\begin{tabular}{cc}
\hline Origin of leaves sample & $\mathrm{IC}_{50}(\mu \mathrm{g} / \mathrm{ml})$ \\
\hline Lumajang & $263.51 \pm 2.18^{\mathrm{a}}$ \\
Makassar & $865.05 \pm 7.68^{\mathrm{b}}$ \\
Trawas & $237.24 \pm 3.41^{\mathrm{c}}$ \\
Agam & $160.80 \pm 6.08^{\mathrm{d}}$ \\
Solok Selatan & $133.37 \pm 2.53^{\mathrm{e}}$ \\
Lampung & $506.07 \pm 2.50^{\mathrm{f}}$ \\
Surabaya & $228.32 \pm 8.92^{\mathrm{c}}$ \\
\hline
\end{tabular}

Results are presented as mean $\pm \mathrm{SD}$ of $\mathrm{IC}_{50}$ (inhibitory concentration 50, $n=$ 3). Means within column with different letters differ significantly $(P<0.05)$.

Table 3: Total phenolics and flavonoids contents of methanol extracts of P. major leaves.

\begin{tabular}{ccc}
\hline Origin of leaves sample & $\begin{array}{c}\text { Total phenolics content } \\
\text { (g of GAE/100 g of } \\
\text { extract) }\end{array}$ & $\begin{array}{c}\text { Total flavonoids } \\
\text { content (g of QE/100 g } \\
\text { of extract) }\end{array}$ \\
\hline Lumajang & $148.84 \pm 6.81^{\mathrm{a}, \mathrm{c}}$ & $19.61 \pm 0.42^{\mathrm{a}}$ \\
Makassar & $134.60 \pm 5.01^{\mathrm{a}}$ & $15.91 \pm 0.81^{\mathrm{b}}$ \\
Trawas & $154.38 \pm 6.50^{\mathrm{a}, \mathrm{c}}$ & $5.12 \pm 0.79^{\mathrm{c}}$ \\
Agam & $210.35 \pm 11.13^{\mathrm{b}}$ & $20.57 \pm 0.41^{\mathrm{a}}$ \\
Solok Selatan & $198.21 \pm 10.61^{\mathrm{b}}$ & $4.61 \pm 1.29^{\mathrm{c}}$ \\
Lampung & $145.52 \pm 1.72^{\mathrm{a}}$ & $8.72 \pm 0.20^{\mathrm{d}}$ \\
Surabaya & $166.67 \pm 5.65^{\mathrm{c}}$ & $8.68 \pm 0.99^{\mathrm{d}}$ \\
\hline
\end{tabular}

Values are means \pm SD of three determinations. Means within each column with different letters differ significantly $(P<0.05)$.

\section{HPTLC fingerprints}

Plantago major leaves from seven locations showed quite similar macroscopic features, thus caused the difficulty in samples discrimination. Moreover, as discussed in the previous section, the presence of oleanolic acid in leaves part could not be detected. In this case, marker approach could not be used to evaluate the identity and quality of $P$. major leaves. Fingerprints approach seemed to be more appropriate than marker approach. To provide informatory and accurate fingerprints, HPTLC conditions were optimized. Figure 1 presents the typical chromatogram-densitogram of $P$. major leaves samples. Eleven up to fifteen peaks were identified in each sample and all existing peaks were considered in the data analysis. All these peaks were then presented in a data matrix (data not shown), $35 \mathrm{x} 15$. Thirtyfive total samples from 7 locations constituted the rows, whereas peak height of each compound appointed the columns.

\section{Chemometrics analysis on HPTLC fingerprints}

\section{Principal component analysis (PCA)}

PCA with full cross validation was applied to the data set of the 35 fingerprints of $P$. major from 7 origins. Analysis was conducted on the peaks height of the full fingerprints without any preprocessing. The PCA model with four principal components (PC) already explained $95 \%$ of total data variance (PC1 captured $63 \%$, PC2 16\%, PC3 9\%, and PC4 7\% of the variance, respectively). The score plot of the first two PC (Figure 2) clearly distinguished seven clusters of samples (L1-L7). The loading plot of the first PC showed that peaks number 10 and 12 are the most important peaks for clustering of samples (Figure 3).

\section{Partial least squares-discrimination analysis (PLS-DA)}

After creating the PCA model to test the presence of clusters, the next step was to build a classification model using algorithm PLS-DA. In this technique, data were analyzed to build a linear discrimination model. The signals (15 peaks height) were used as $\mathrm{X}$ variables, whereas the $\mathrm{Y}$ 


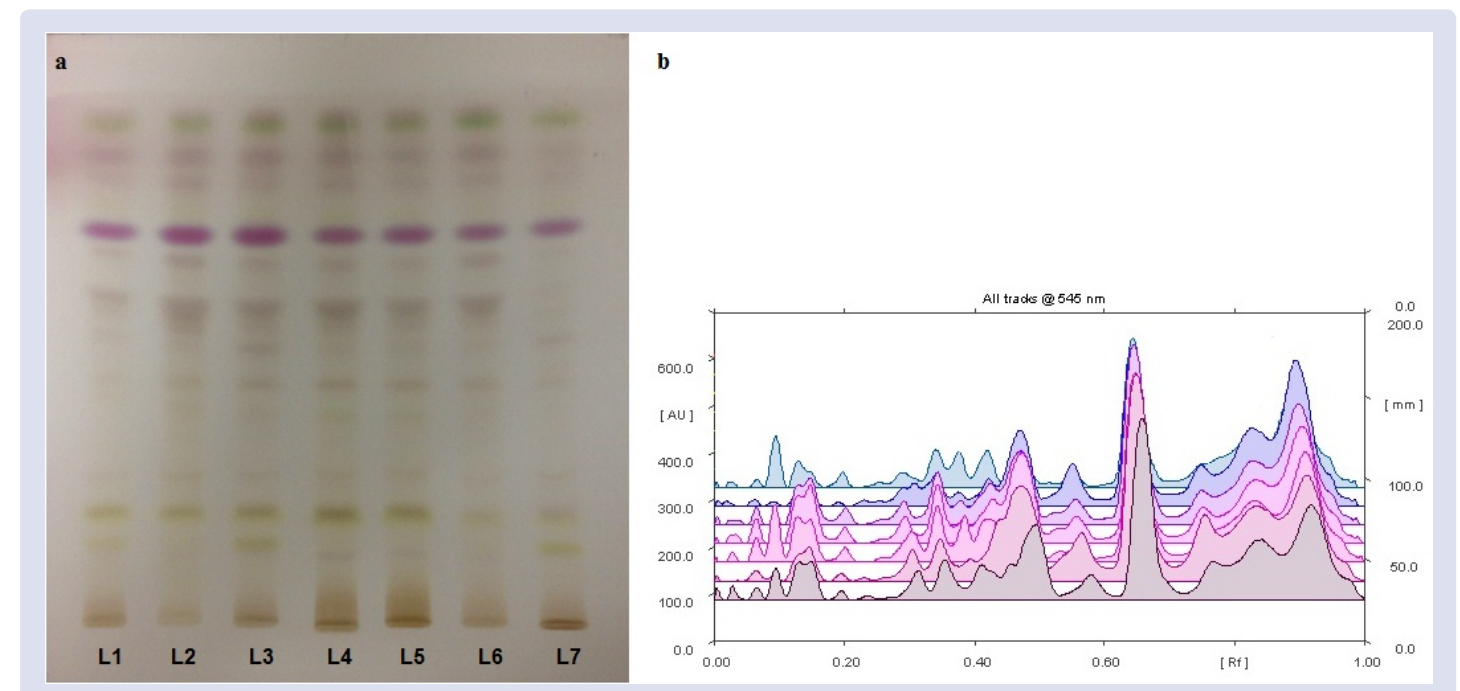

Figure 1: HPTLC-fingerprints of $P$. major leaves (a) and their densitograms (b). L1, L2, L3, L4, L5, L6, and L7 are leaves samples from Lumajang, Makassar, Trawas, Agam, Solok Selatan, Lampung, and Surabaya, respectively.

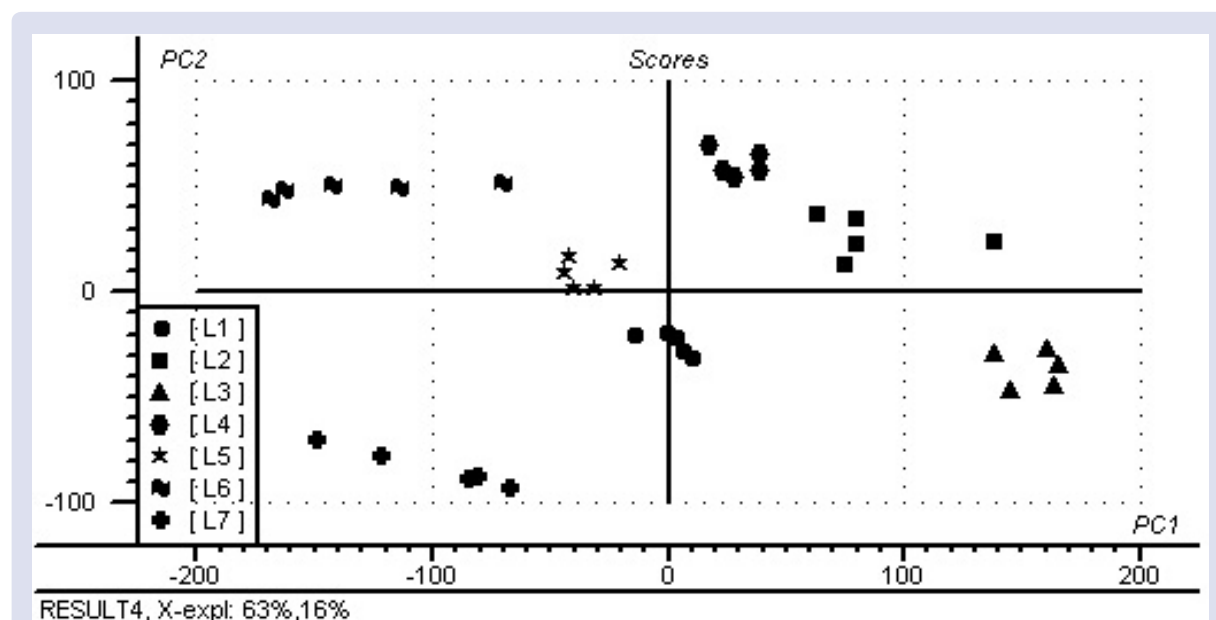

RESULT4, X-expl: $63 \%, 16 \%$

Figure 2: PCA score plot of $P$. major from different origins on the first two PCs (PC1 vs. PC2).

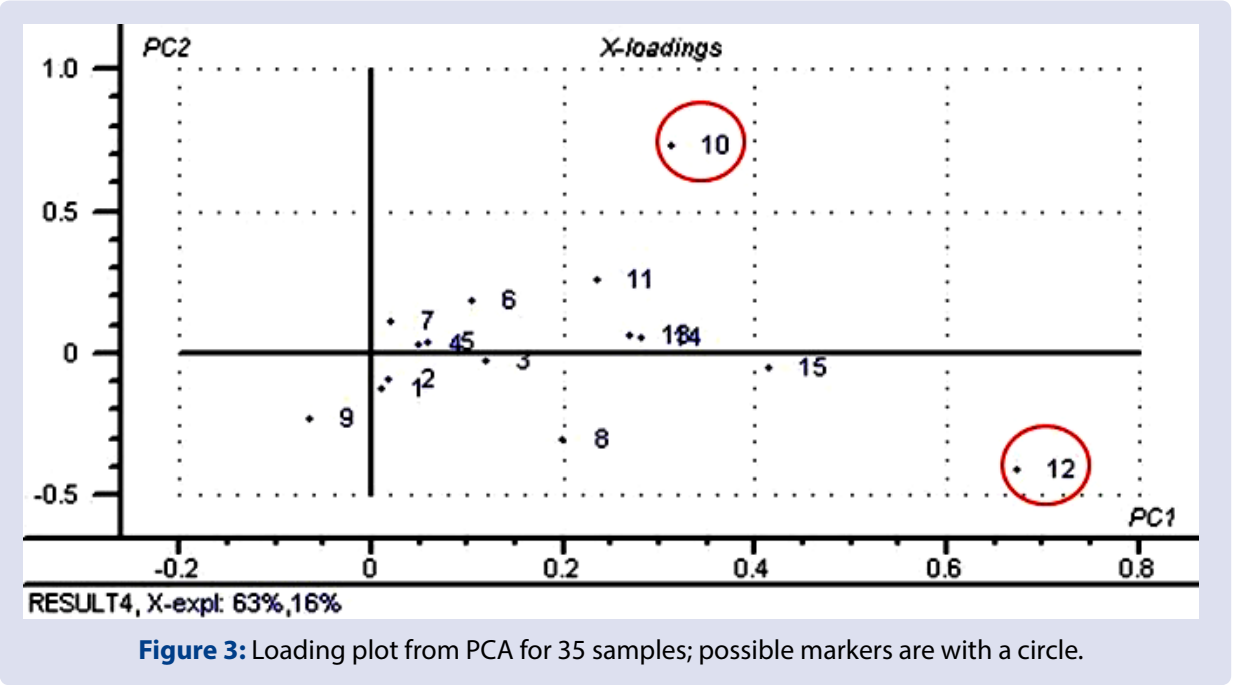




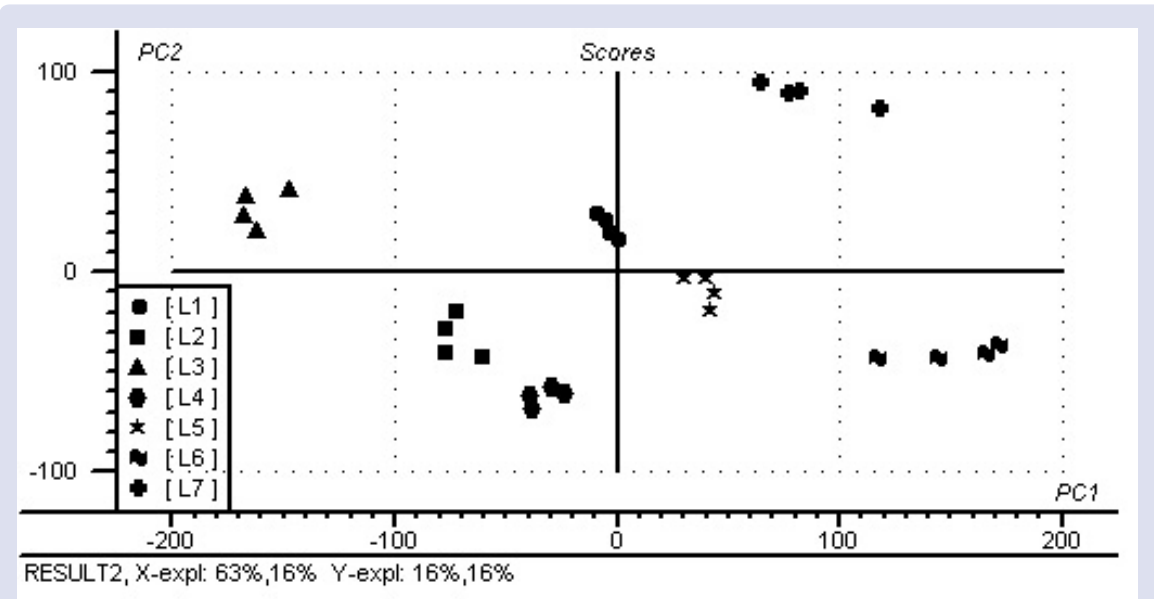

Figure 4: PLS-DA score plot of P. major from different origins on the first two PCs (PC1 vs. PC2).

Table 4: Result of classification of the P. major leaves samples for the prediction of samples not used in calibration (external validation data set).

\begin{tabular}{cccccccccccccccc}
\hline Sample & \multicolumn{1}{c}{ L1 } & \multicolumn{1}{c}{ L2 } & \multicolumn{1}{c}{ L3 } & \multicolumn{2}{c}{ Classes } \\
\multicolumn{1}{r}{} & L1-prd & L1-ref & L2-pred & L2-ref & L3-pred & L3-ref & L4-pred & L4-ref & L5-pred & L5-ref & L6-pred & L6-ref & L7-pred & L7-ref \\
\hline L1-v & $\mathbf{0 . 9 7 4}$ & 1 & -0.012 & 0 & 0.026 & 0 & 0.089 & 0 & 0.013 & 0 & -0.080 & 0 & -0.009 & 0 \\
L2-v & 0.032 & 0 & $\mathbf{0 . 9 7 3}$ & 1 & -0.028 & 0 & -0.115 & 0 & 0.059 & 0 & -0.064 & 0 & 0.142 & 0 \\
L3-v & 0.038 & 0 & 0.038 & 0 & $\mathbf{0 . 8 7 6}$ & 1 & -0.062 & 0 & 0.064 & 0 & 0.035 & 0 & 0.042 & 0 \\
L4-v & 0.088 & 0 & -0.019 & 0 & -0.029 & 0 & $\mathbf{0 . 9 8 5}$ & 1 & -0.094 & 0 & 0.093 & 0 & -0.024 & 0 \\
L5-v & 0.028 & 0 & -0.024 & 0 & 0.049 & 0 & 0.017 & 0 & $\mathbf{0 . 9 7 5}$ & 1 & 0.020 & 0 & -0.065 & 0 \\
L6-v & -0.046 & 0 & 0.018 & 0 & 0.016 & 0 & 0.060 & 0 & -0.050 & 0 & $\mathbf{0 . 9 8}$ & 1 & 0.022 & 0 \\
L7-v & 0.020 & 0 & -0.026 & 0 & 0.009 & 0 & -0.023 & 0 & 0.043 & 0 & -0.016 & 0 & $\mathbf{0 . 9 9 3}$ & 1 \\
\hline
\end{tabular}

L1, L2, L3, L4, L5, L6, and L7 represent leaves samples from Lumajang, Makassar, Trawas, Agam, Solok Selatan, Lampung, and Surabaya, respectively; -v means sample from related class used for validation set. Pred.: predicted; Ref.: reference.

variables were associated with the seven sample classes (one different $\mathrm{Y}$ variable for each leaves sample, with 1 or 0 depending on whether it belongs or not to the considered data group). The model obtained in this study was able to discriminate among the seven samples, as it can be seen from the PLS-DA score plot in Figure 4, where now the clusters are better distinguished than PCA cluster.

Statistical parameters of the results were obtained by PLS-DA model using the 28 calibration samples. High correlation between measured and predicted classes $\left(R^{2}\right.$ in calibration is 0.9826$)$ and low prediction errors (RMSE in calibration is 0.04 ) were obtained. The defined PLSDA model was applied to classify 7 leaves samples (1 from each class) of the external validation subset. According to PLS-DA rules, a sample was considered belonging to a class when a predicted value of $y$ was comprised between 0.5 and 1.5 for that class. Table 4 shows that for the validation samples, a $100 \%$ correct classification was achieved. The predicted values by the PLS-DA model were always very close to 1 (0.876-0.993). These results confirmed that the predictive ability of the developed classification model was very good. Therefore, it was concluded that combination of HPTLC fingerprints with chemometrics techniques, PCA and PLS-DA, has demonstrated a great potential in the discrimination and classification of herbal materials.

\section{CONCLUSIONS}

Plantago major collected from different origins in Indonesia revealed different radical scavenging activity and concentration of total phenolics as well as total flavonoids. Moreover, HPTLC fingerprint combined with the chemometrics (PCA and PLS-DA) was able to discriminate among the leaves of Plantago major originated from various locations. Chemical compounds represented by peaks number 10 and 12 on the HPTLC fingerprint are considered as the most important compounds for clustering of Plantago major.
Development of analytical methods for geographical origins of $P$. major will have positive implications for the quality control of herbal materials which will ultimately guarantee the safety and efficacy of the product.

\section{ACKNOWLEDGEMENTS}

We thank to Ministry of Research, Technology, and Higher Education of the Republic of Indonesia who was supported this research under Applied Research Scheme as well as Fundamental Research Scheme with the contract number: 120/SP2H/LT/DRPM/IV/2017 and 004/ SP2H/LT/MULTI/L7/2019, respectively. We also acknowledge The University of Surabaya for financially support this work under Competitive Research Scheme with the contract number: 017/SP-Lit/ LPPM-01/Int/FF/III/2019.

\section{REFERENCES}

1. Samuelsen $A B$. The traditional uses, chemical constituents and biological activities of Plantago major L. A review. J Ethnopharmacol. 2000;71(1-2):1-21.

2. Kartini, Piyaviriyakul S, Thongpraditchote S, Siripong P, Vallisuta O. Effects of Plantago major extracts and its chemical compounds on proliferation of cancer cells and cytokines production of lipopolysaccharide-activated THP-1 macrophages. Pharmacognosy Magazine. 2017;13(51):393-9.

3. Beara IN, Orčić DZ, Lesjak MM, Mimica-Dukić NM, Peković BA, Popović MR. Liquid chromatography/tandem mass spectrometry study of anti-inflammatory activity of Plantain (Plantago L.) species. J Pharm Biomed Anal. 2010;52(5):7016.

4. Ringbom T, Segura L, Noreen Y, Perera P, Bohlin L. Ursolic acid from Plantago major, a selective inhibitor of cyclooxygenase-2 catalyzed prostaglandin biosynthesis. J Nat Prod. 1998;61(10):1212-5.

5. Stenholm A, Goransson U, Bohlin L. Bioassay-guided supercritical fluid extraction of cyclooxygenase-2 inhibiting substances in Plantago major L. Phytochem Anal. 2013;24(2):176-83. 
6. Núñez Guillén ME, da Silva Emim JA, Souccar C, Lapa AJ. Analgesic and Anti-inflammatory Activities of the Aqueous Extract of Plantago major L. Pharmaceutical Biology. 1997;35(2):99-104.

7. Türel I, Özbek H, Erten R, Öner AC, Cengiz N, Yilmaz O. Hepatoprotective and anti-inflammatory activities of Plantago major L. Indian Journal of Pharmacology. 2009;41(3):120.

8. Zubair M, Ekholm A, Nybom H, Renvert S, Widen C, Rumpunen K. Effects of Plantago major $\mathrm{L}$. leaf extracts on oral epithelial cells in a scratch assay. Journal of Ethnopharmacology. 2012;141(3):825-30.

9. Chiang LC, Chiang W, Chang MY, Lin CC. In vitro cytotoxic, antiviral and immunomodulatory effects of Plantago major and Plantago asiatica. Am J Chin Med. 2003;31(2):225-34.

10. Chiang LC, Chiang W, Chang MY, Ng LT, Lin CC. Antiviral activity of Plantago major extracts and related compounds in vitro. Antiviral Research. 2002;55(1):53-62

11. Galvez M, Martin-Cordero C, Lopez-Lazaro M, Cortes F, Ayuso MJ. Cytotoxic effect of Plantago spp. on cancer cell lines. J Ethnopharmacol. 2003;88(23):125-30.

12. Kolak $U, B o \cdot a ~ M$, Uruşak EA, Ulubelen A. Constituents of Plantago major subsp. intermedia with antioxidant and anticholinesterase capacities. Turkish Journal of Chemistry. 2011;35(4):637-45.

13. Gomez-Flores R, Calderon C, Scheibel L, Tamez-Guerra P, Rodriguez-Padilla C, Tamez-Guerra R, et al. Immunoenhancing properties of Plantago major leaf extract. Phytotherapy Research. 2000;14(8):617-22

14. Beara IN, Lesjak MM, Jovin EĐ, Balog KJ, Anackov GT, Orcic囚 DZ, et al. Plantain (Plantago L.) species as novel sources of flavonoid antioxidants. Journal of Agricultural and Food Chemistry. 2009;57(19):9268-73.

15. Heo B-G, Park Y-J, Park Y-S, Bae J-H, Cho J-Y, Park K, et al. Anticancer and antioxidant effects of extracts from different parts of indigo plant. Industrial Crops and Products. 2014;56(0):9-16.

16. Li H, Deng Z, Liu R, Zhu H, Draves J, Marcone M, et al. Characterization of phenolics, betacyanins and antioxidant activities of the seed, leaf, sprout, flower and stalk extracts of three Amaranthus species. Journal of Food Composition and Analysis. 2015;37:75-81.

17. Tres A, Ruiz-Samblas C, van der Veer G, van Ruth S. Geographical provenance of palm oil by fatty acid and volatile compound fingerprinting techniques. Food Chemistry. 2013;137(1):142-50.

18. Wang Y, Han T, Zhang X-G, Zheng C-J, Rahman K, Qin L-P. LC Fingerprint and hierarchical cluster analysis of Crocus sativus L. from different locations in China. Chromatographia. 2009;70(1-2):143-9.
19. Gad HA, El-Ahmady SH, Abou-Shoer MI, Al-Azizi MM. Application of chemometrics in authentication of herbal medicines: a review. Phytochem Anal. 2013;24(1):1-24

20. Li S, Han Q, Qiao C, Song J, Cheng CL, Xu H. Chemical markers for the quality control of herbal medicines: an overview. Chinese Medicine. 2008;3(1):7.

21. Chen Y, Zhu SB, Xie MY, Nie SP, Liu W, Li C, et al. Quality control and original discrimination of Ganoderma lucidum based on high-performance liquid chromatographic fingerprints and combined chemometrics methods. Anal Chim Acta. 2008;623(2):146-56.

22. Tistaert C, Dejaegher B, Heyden YV. Chromatographic separation techniques and data handling methods for herbal fingerprints: a review. Analytica Chimica Acta. 2011;690(2):148-61.

23. Komsta $Ł$. Chemometrics in fingerprinting by means of thin laye chromatography. Chromatography Research International. 2011;2012.

24. Bansal A, Chhabra V, Rawal RK, Sharma S. Chemometrics: a new scenario in herbal drug standardization. Journal of Pharmaceutical Analysis. 2014;4(4):223-33.

25. Kartini, Piyaviriyakul S, Siripong P,Vallisuta O. HPTLC simultaneous quantification of triterpene acids for quality control of Plantago major $\mathrm{L}$. and evaluation of their cytotoxic and antioxidant activities. Ind Crop Prod. 2014;60(0):239-46.

26. Galvez M, Martin-Cordero C, Houghton PJ, Ayuso MJ. Antioxidant activity of methanol extracts obtained from Plantago species. J Agric Food Chem. 2005;53(6):1927-33.

27. Jurišica R, Debeljakb Ze, Vladimir-Knezevica S, Vukovica J. Determination of aucubin and catalpol in Plantago species by micellar electrokinetic chromatography. Z Naturforsch 59c. 2004:27-31.

28. Olennikov D, Tankhaeva L, Samuelsen A. Quantitative analysis of polysaccharides from Plantago major leaves using the Dreywood method. Chemistry of Natura Compounds. 2006;42(3):265-8.

29. Tarvainen M, Suomela J-P, Kallio H, Yang B. Triterpene Acids in Plantago major Identification, Quantification and Comparison of Different Extraction Methods. Chromatographia. 2010;71(3-4):279-84.

30. Zacchigna M, Cateni F, Faudale M, Sosa S, Loggia RD. Rapid HPLC analysis for quantitative determination of the two isomeric triterpenic acids, oleanolic acid and ursolic acid, in Plantago major. Scientia Pharmaceutica. 2009;77(1):79-86.

31. Chen Z, Bertin R, Froldi G. EC50 estimation of antioxidant activity in DPPH assay using several statistical programs. Food Chemistry. 2013;138(1):414-20.

32. Singleton VL, Orthofer R, Lamuela-Raventos RM. Analysis of total phenols and other oxidation substrates and antioxidants by means of folin-ciocalteu reagent. Methods in Enzymology. 1999(299C):152-78.

33. Chang C-C, Yang MH, Wen HM, Chern JC. Estimation of total flavonoid content in propolis by two complementary colorimetric methods. Journal of Food and Drug Analysis. 2002;10(3):178-82.

\section{GRAPHICAL ABSTRACT}

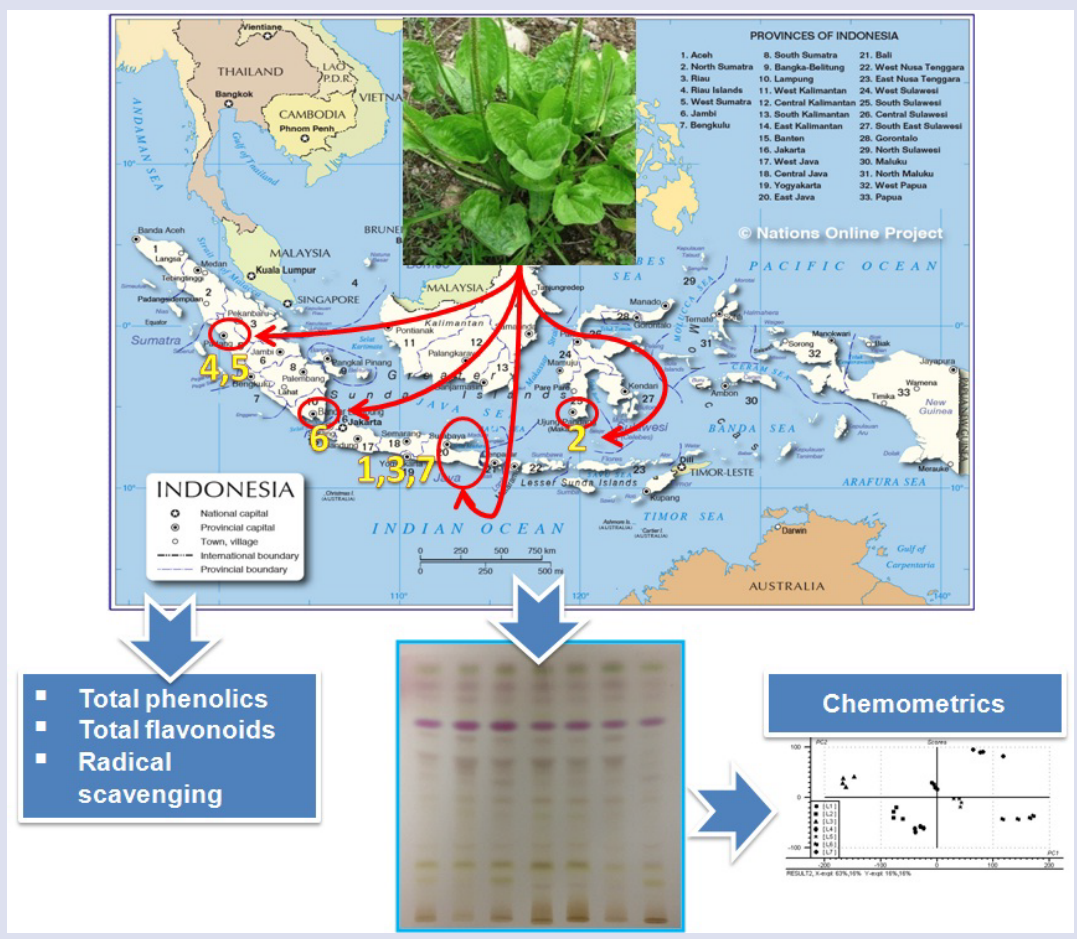



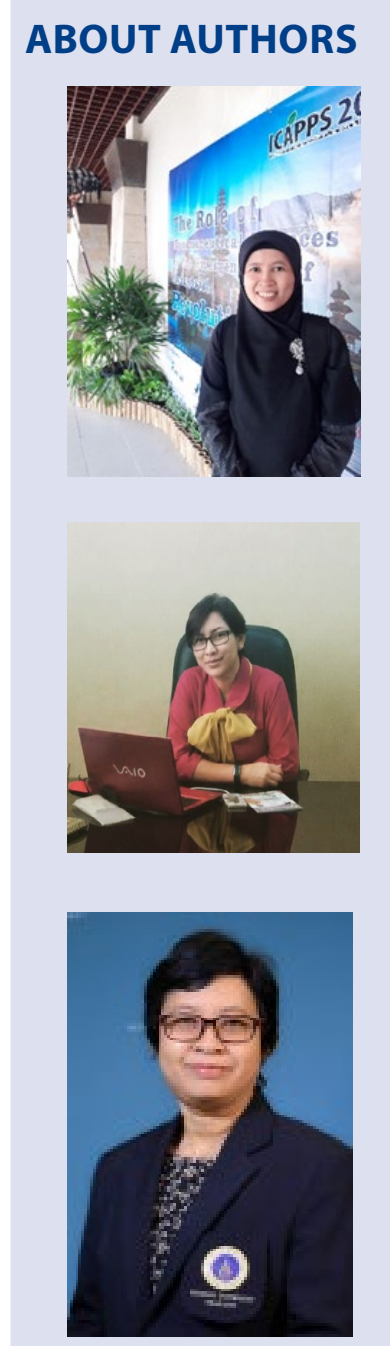

Christina Avanti, Ph.D. is an Associate Professor, Vice Rector for Student Affairs and Alumni, Former Dean of Faculty of Pharmacy University of Surabaya, Indonesia. PhD graduated in Pharmacy at the Department of Pharmaceutical Technology and Biopharmacy University of Groningen. She is currently working in several projects developing techniques to improve bioavailability and stability of lipophilic pharmaceuticals and develop modified delivery system of Indonesian medicinal plants.

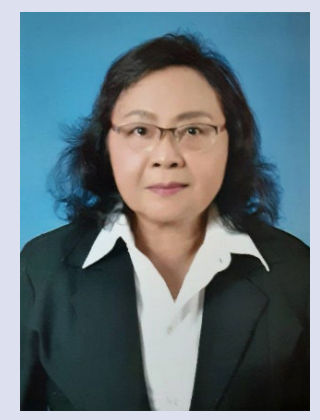

Dr. Chutima Phechkrajang is an Associate Professor of Pharmaceutical Chemistry at Faculty of Pharmacy, Mahidol University, Thailand. She has graduated her Ph.D. in Analytical Chemistry, Faculty of Sciences, Mahidol University. She has conducted chemometrics researches more than 10 years and continuously published the applications of chemometrics in pharmaceutical and phytopharmaceutical analysis.

Dr. Omboon Vallisuta is an Associate Professor in the Department of Pharmacognosy, Faculty of Pharmacy, Mahidol University, Thailand where she received her first degree in Pharmacy with honor. She got her Ph.D. in Phytochemistry from the Department of Pharmacy, University of Queensland, Australia. She has over 30 years experiences in teaching (under and postgraduates courses) and research in Pharmacognosy and Phytochemistry. Supervising more than 40 senior projects, Master and Ph.D. theses, she has published more than 80 book chapters, peer reviewed journal articles and presentations in scientific conferences. She served as Chief Editor of The Mahidol Journal of Pharmaceutical Sciences (during 1994-1997) and three books for Intech, Croatia (2012-2015). For international communities she gave consultancy services many times to Bhutan governmental unit and private company in the area of medicinal plants and natural products (2007-2009). Her interests are traditional medicines and natural products in the scope of biotechnology, quality control, biological activity testing, SPA products and innovation.

Cite this article: Kartini K, Avanti C, Phechkrajang C, Vallisuta O. Antioxidant Activity, HPTLC Fingerprint, and Discriminant Analysis of Plantago major Leaves from Diverse Origins in Indonesia. Pharmacog J. 2019;11(6)Suppl:1483-9. 